\title{
Consumer Governance in Electricity Markets
}

\author{
Toby Daglish*
}

February 18, 2015

\begin{abstract}
This paper examines switching decisions by households in the MainPower distribution area of New Zealand. The paper measures the extent to which customers switched in response to information about directors' bonuses, marketing surrounding firm ownership, and work by the New Zealand Electricity Authority to promote switching behaviour. The first two events demonstrate the magnitude of consumer concerns about firm governance in an Electricity market. The latter provides a measure of search costs in a market where no central switching service is provided.
\end{abstract}

Retail customers play an important role in the risk-management strategies of gentailer companies. Firms who have retail market shares equal to their production shares are less inclined to exert market power in wholesale markets, and are also, given the fixed prices negotiated with customers, relatively immune to fluctuations in wholesale prices (Bushnell, Mansur, and Saravia (2008)). Risk management may encourage gentailers to target a particular market share. More aggressive firms may choose to take a position that leaves them as net buyers or sellers in the wholesale market. In either case, however, a firm will frequently have a desired level of retail market penetration.

*New Zealand Institute for the Study of Competition and Regulation. The author thanks Yiğit Sağlam, Oliver Robertson, Dayle Parris, Jean-Pierre Florens, Beverly Brereton, Andrew Kerr, participants at the ATE workshop 2013, TIGER forum 2014, along with staff of Meridian Energy, IPEA, and the New Zealand Electricity Authority for their feedback at seminars. The author thanks MainPower for providing customer switching data, and Stephen Burrough for providing assistance with identifying price change dates. Research Assistant support was provided by Richard Law. 
A regulator concerned with market power, in contrast, may desire firms' market shares to align with their productive capacity. The regulator may also want to see customers exhibiting elastic demand for electricity, thereby moving oligopolistic supply in the market closer to competitive equilibria. These two objectives encourage a regulator to first encourage hedging by firms (whether through derivative contracts or vertical integration) and second to encourage customers to move retailers in response to price competition. Giulietti, Grossi, and Waterson (2010a) shows that, in the English/Welsh market, there is a weak link between wholesale prices and retail prices, meaning that market power in the retail market is an important determinant of consumer prices.

The behaviour of customer switching in electricity markets is thus of interest to both firms who are targeting one particular market share and also regulators who may be targeting another particular set of market shares, and hoping to achieve a healthy level of "churn" amongst customers. This paper seeks to explore the motivations behind electricity retail customer movements.

Brennan (2007) reports that most jurisdictions, with the exception of Britain, have exhibited very low switching rates, as customers seem reluctant, in deregulated markets, to move from their initially assigned retailer. He notes that New Zealand has the second highest switching rate, but that this still leaves $75 \%$ of customers having not switched (at time of writing). Defeuilley (2009) attributes low switching rates and suboptimal behaviour of households to behavioural biases encouraging customers to stick with the "status quo", and risk aversion. He also comments that in many cases retail offerings have been less innovative than would be expected, and customers may not have been offered something "new" by incoming retailers. Defeuilley's view is consistent with Giulietti, Waddams, and Waterson (2005)'s survey evidence that search costs are perceived to be high for many customers. In contrast, Littlechild (2009) remarks that most deregulated markets are seeing growing switching behaviour over time. Economically, this is important for retailers: Giulietti, Otero, and Waterson (2010b) document that since privatisation, in the the UK market, prices for incumbents have not converged, presumably suggesting that they can exploit inertia in customer switching decisions (Puller and West 
(2013) makes similar observations for the US market, while Su (2014) notes that US price declines were concentrated in early years of deregulation rather than ongoing). In a subsequent working paper (Giulietti, Waterson, and Wildenbeest (2010c)), the authors use a theoretical model of customer reluctance to switch to infer customer search costs from the dispersion of prices. Some level of obfuscation may be in the interests of market participants, as shown by Kalayci and Potters (2010). Wilson and Waddams Price (2010) shows that although most customers who had switched retailers were motivated by costs, a fifth of customers lost economic surplus by switching. Waddams Price and Zhu (2013) notes that UK retailers had followed the practice of pricing higher in their "home" jurisdictions than they do when competing in other regions; this practice being banned in 2009 .

We hypothesise that retail customers are motivated by several factors in making a decision to switch retailers. First, we assume that customers are motivated by price concerns. If a competitor offers a lower price, customers will be inclined to switch retailer. This is mitigated by search costs, and so customers may not move if the gains from switching are small. Secondly, however, customers may be motivated by their opinions of the companies concerned. Electricity is a homogeneous product, but electricity retailers may need to be concerned about their corporate image. Thirdly, many customers may be unaware of the possibility of switching, or may have partial information regarding the benefits that can be gained. Hence we might expect that marketing on the part of a regulator who makes this information available to customers may result in more fluid switching behaviour.

This paper makes use of an extensive data set covering the North Canterbury region of New Zealand, provided by the local Lines Company, MainPower. The New Zealand electricity market separates retail and generation activities from ownership of distribution networks. Retailers compete for customers in a region, but the lines company has a monopoly on distribution activities. As such, MainPower observes all switching activity in the region.

We examine the transfers between retailers of ICPs (individual meters) to changes in 
retail prices. We also examine the responses of customers to three events. First, we examine the response of customers to Contact Energy's Directors' remuneration. In September 2008, Contact announced that it was jointly raising retail prices, and also paying substantial bonuses to its Directors. We examine whether this event caused increased switching activity amongst customers; were customers concerned with the governance of Contact's board? Second, we examine a marketing campaign, in which Trustpower marketed itself as being more desirable on the strength of being a trust (as opposed to a company, as is the case for most other retailers). Did customer response to this campaign indicate a preference over ownership structure for their retailer? In this regard, we examine consumer desire to engage in "ethical" behaviour. Sen, G urhan-Canli, and Morwitz (2001) argue that even in the presence of an organised boycott of a particular product, consumers have weak incentives to participate: at the margin, they are unlikely to achieve change, and potentially face high costs in terms of suboptimal consumption patterns to achieve this. On the other hand, Bénabou and Tirole (2006) argue that individuals may engage in ethical behaviour as a signalling tool. By engaging in costly activities, an individual signals that they may have preferences of a particular type, which allows them to relate to others with similar preferences. This is potentially an economically significant issue: Arnot, Boxall, and Cash (2006) shows that in the coffee market, fair trade coffee has a markedly lower price elasticity than other products, implying that under oligopolistic competition, ethical products may have higher profit margins.

Lastly, we examine the introduction of the "What's my Number?" campaign by the Electricity Authority. In this campaign, the market regulator provided a website to help customers estimate the savings they could achieve by switching retailer. By examining this event, we see whether educational work by the regulator can lower switching costs and achieve a higher rate of customer movement.

Existing empirical work on individual customer switching behaviour has been sparse. Giulietti et al. (2005) examine behaviour of gas customers in the United Kingdom, who face the opportunity of switching from British Gas to new entrants in the market. Hortaçsu, Madanizadeh, and Puller (2014) study the switching behaviour of Texas 
residents in the wake of deregulation. Giulietti et al.'s (2005) survey data shows that old age pensioners are considerably less likely to switch retailers, while more densely populated areas are fruitful grounds for customer mobility, and likely to be targetted by retailers looking to poach customers.

The layout of the remainder of this paper is as follows. Section 1 outlines our methodology. Section 2 describes our data set. Section 3 presents the empirical results of our work, while Section 4 concludes.

\section{Methodology}

This paper makes use of the Conditional Logit model (McFadden (1973)) to explain household switching behaviour. We assume that household $i$ in month $t$ receives utility from retailer $j$ according to the following equation

$$
U_{i, j, t}=\sum_{k} \beta_{k} X_{i, j, t, k}+\epsilon_{i, j, t}
$$

where $X_{i, j, t}$ are a set of characteristics that vary across households, retailers and time. These are observable to the econometrician. $\epsilon_{i, j, t}$ is a term that is unobservable to the econometrician, but assumed to be logistically distributed. As such, we can evaluate the probability that a household chooses a particular retailer $(j)$ as

$$
\frac{e^{\sum_{k} \beta_{k} X_{i, j, t, k}}}{\sum_{j^{\prime}} e^{\sum_{k} \beta_{k} X_{i, j^{\prime}, t, k}}}
$$

With this set of probabilities, the parameters $\left(\beta_{k}\right)$ can be found by maximising the likelihood that a household chooses the particular retailer observed in a particular month, i.e.:

$$
\max _{\beta_{1}, \ldots, \beta_{N}} \prod_{i} \prod_{t} \frac{e^{\sum_{k} \beta_{k} X_{i, j(i, t), t, k}}}{\sum_{j^{\prime}} e^{\sum_{k} \beta_{k} X_{i, j^{\prime}, t, k}}}
$$

where $j(i, t)$ is household $i$ 's observed time $t$ choice of retailer. In our estimation of standard errors, we allow for clustering across households, following Cameron, Gelbach, and Miller (2011). 


\subsection{Price effects}

We assume that households have a preference for cheaper retail rates, so our first explanatory variable is relative price:

$$
X_{i, j, t, 1}=\frac{P_{j, t}}{P_{j(i, t-1), t}},
$$

i.e. the price of a competitor relative to the household's incumbent retailer. This effect is offset by search costs, ans we therefore allow our second term to be a preference for the household's incumbent retailer:

$$
X_{i, j, t, 2}= \begin{cases}1 & \text { if } j=j(i, t-1) \\ 0 & \text { otherwise. }\end{cases}
$$

A high estimate for $\beta_{2}$ therefore represents higher search costs, manifested as greater inertia amongst customers. By interacting demographic or time series variables with $X_{i, j, t, 2}$ we can examine the effect of variables that might increase/decrease inertia (such as the "What's my number?" campaign). By interacting variables with $X_{i, j, t, 1}$ we can examine variables that might increase a household's sensitivity to prices (such as seasonal/weather variables that might proxy for a household having experienced high power bills).

Hortaçsu et al. (2014) highlight the importance of identification of inertia effects in a model, and point out that including firm dummies cannot explain the long periods that customers spend with individual retailers. In their model, they break the switching decision into a two-step process, where customers first make a decision to "shop around", while in the second stage, they choose a retailer from the set of competitors. In our case, we incorporate the first decision into our model by way of the incumbent dummy: most customers will have a substantial preference for their existing retailer in a given month, resulting in long periods with no switching for most customers. We believe that this achieves a similar outcome to Hortaçsu et al.'s (2014) approach, and by interacting with price effects we can model customers becoming more or less active in the market. Where we feel our approach has a slight advantage is in interpretation: since the coefficients are 
being estimated in the same logit formulation, it is easy for us to interpret the economic significance of inertia, as demonstrated in Section 3.2. In section 3.2.1, we check the robustness of our approach by considering a sub-sample of customers, restricted to be only those who switch at least once in the sample.

\section{Data}

Our data covers the period May 2007-December 2012. The data used in this project can be split into four subsets: switching data, electricity usage, demographics and weather information.

\section{$2.1 \quad$ Switching}

Switching information is provided by MainPower, the lines company who provides distribution services in North Canterbury. Data is anonymised by meshblock, and covers all connections and terminations.

Figure 1 shows the dispersion of ICPs across the region, and provides an idea of the demographic character of North Canterbury. The region contains some urban areas in the South: Rangiora and Kaiapoi. There are also some smaller towns scattered across the region: Kaikoura, Waipara, and Culverden. The region is also characterised by large rural areas. North Canterbury has varied terrain; the region is dominated by the Canterbury plain, but in the West is bounded by the Southern Alps, and in the North by the hills surrounding Kaikoura.

The region is divided into seven Grid Exit Points (GXPs) where each ICP is assigned to one GXP (see 1). Ashley11 includes a direct connection to the transmission network by a fibre board factory. We exclude Ashley11 from our work on electricity usage, since its offtake is dominated by the fibre board factory. However, since many small ICPs are also connected, we include Ashley11 ICPs in our switching work.

There are 38880 ICPs in the region, and we observe 16633 switches during the period. A histogram of number of switches observed for each ICP is given in figure 2 . 


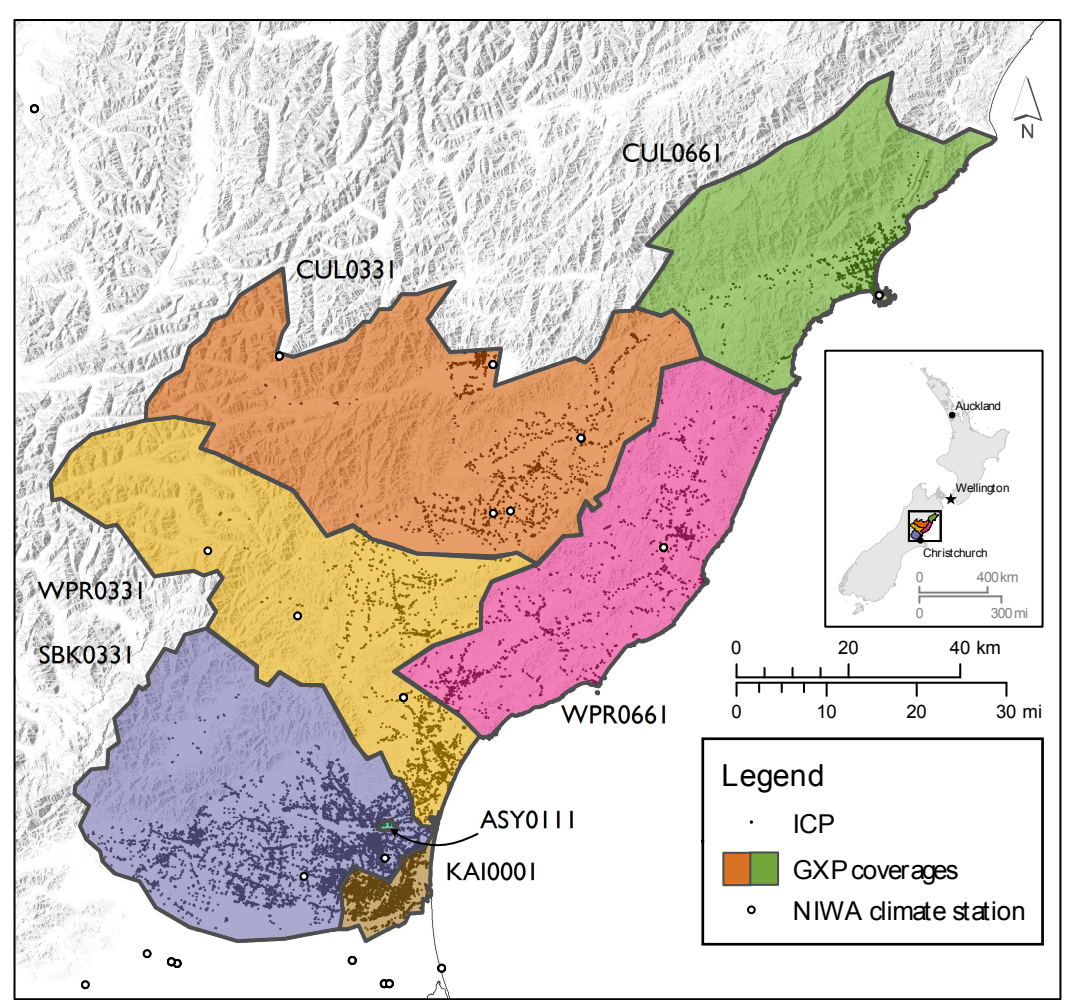

Figure 1: The MainPower region.

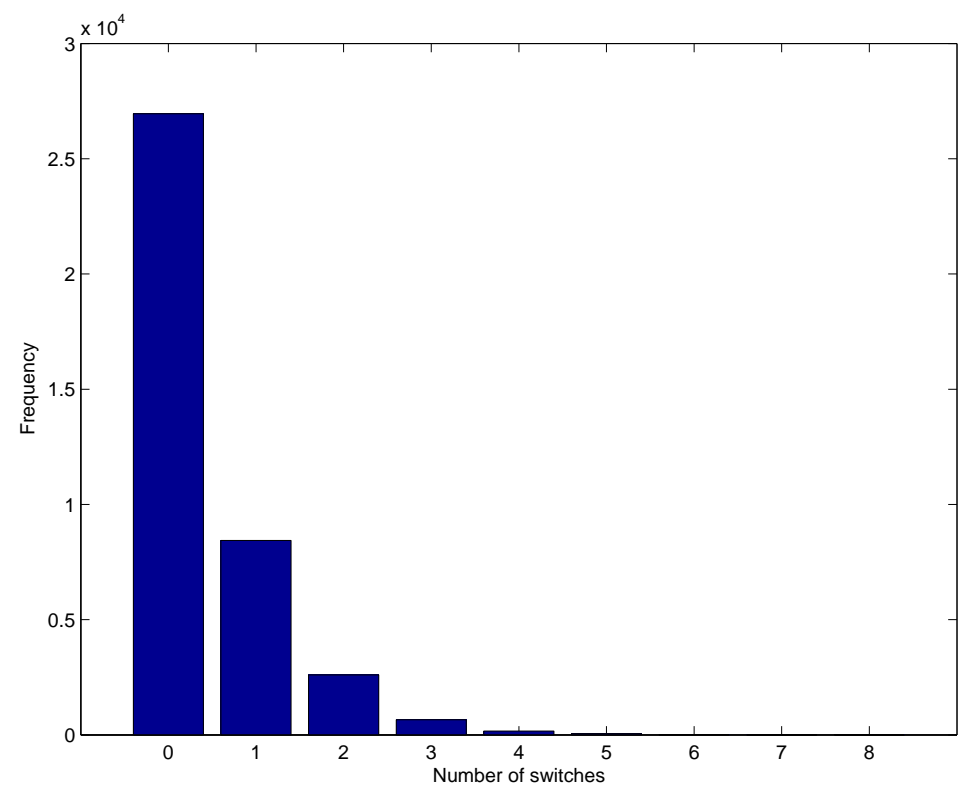

Figure 2: Histogram of number of switches for an ICP in the MainPower region. 


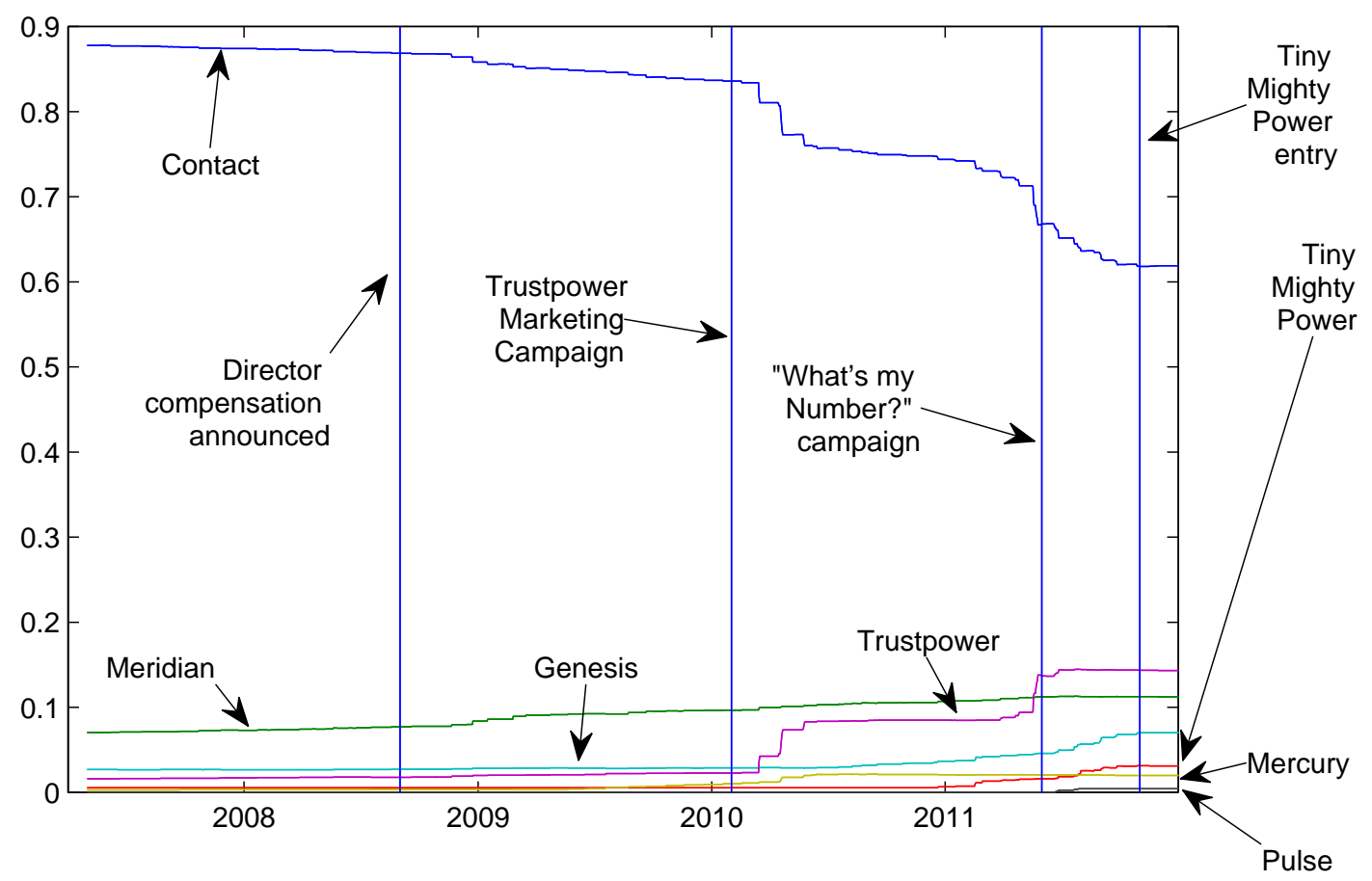

Figure 3: Market shares (as percentage) for the MainPower region.

Contact Energy is the incumbent firm from deregulation, and at the start of the sample, accounts for roughly $90 \%$ of ICPs in the region. Over the course of the sample period, this portion declines and the retail shares become more evenly distributed across retailers, see figure 3 .

\section{$2.2 \quad$ Electricity Usage}

Electricity offtakes are available at a Grid Exit Point (GXP) level (see figure 1). We aggregate daily offtakes into monthly observations (see figures 5 and 6). Electricity use fluctuates in most areas, and often shows strong seasonal patterns. These patterns can exhibit high mid-year (winter) usage (see for example Kaiapoi11) or high year end (summer) usage (see for example Waipara33). 


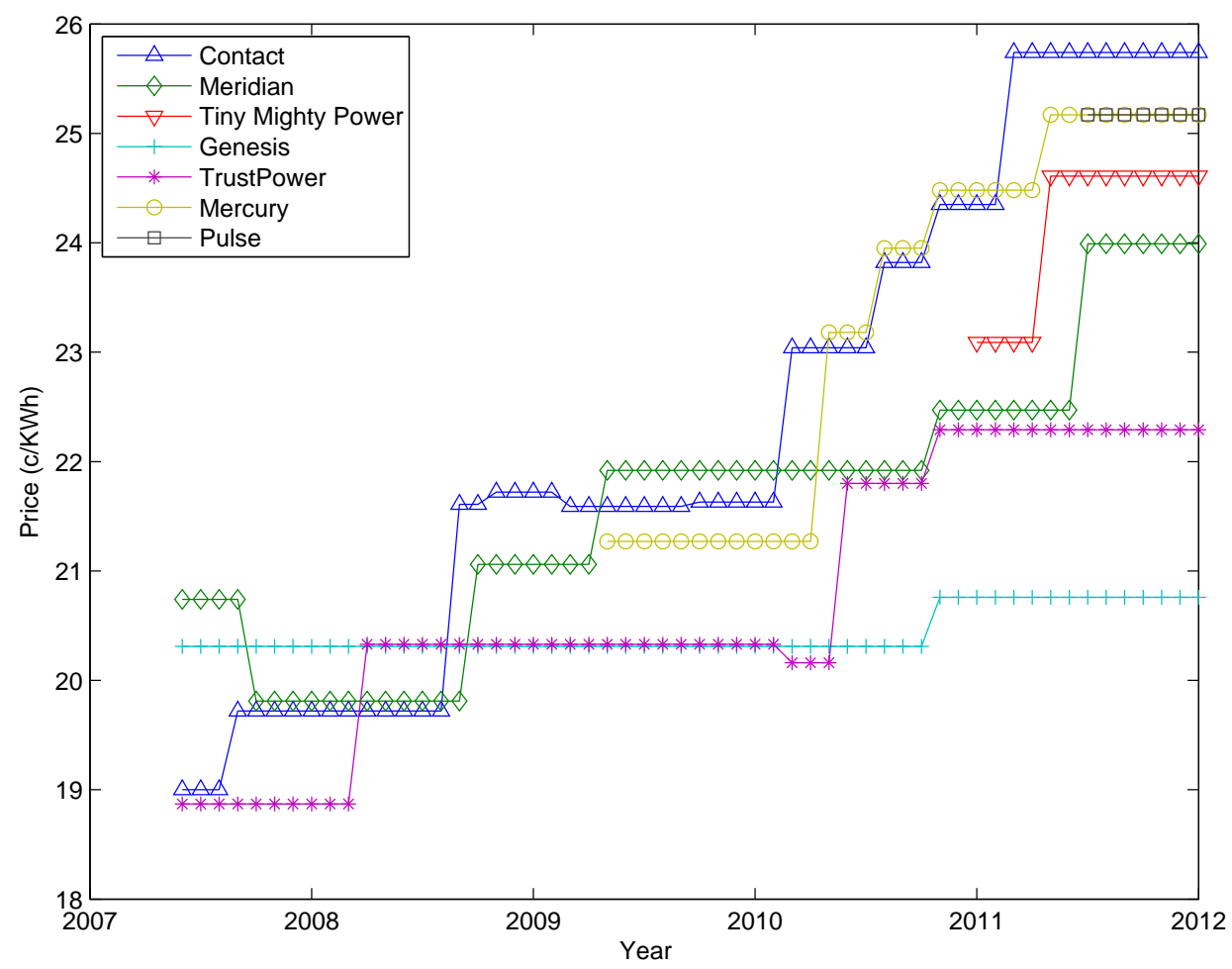

Figure 4: Prices offered by retailers for the MainPower region. Note that Kaiapoi customers, due to a slightly different contractual arrangement with the MainPower lines company, can, theoretically be offered a different tariff to other customers. The prices listed here are for non-Kaiapoi customers; differences for Kaiapoi customers are minimal (Genesis Kaiapoi customers saved 2.15 c/KWh extra in May-August 2007, TrustPower Kaiapoi customers paid an extra 0.11 c/KWh from May-September 2010, and 0.12 c/KWh thereon). Tiny Mighty Power was only available in Kaiapoi, so the prices listed here are for Kaiapoi customers. 


\subsection{Demographics}

Since our data is anonymised at a Meshblock level, we can connect our switching data to Statistics New Zealand data concerning house sizes, and general demographic information for the area.

We further create GXP level information by weighting meshblock information according to the number of ICPs attached to a particular GXP that lie in each meshblock. GXP level information is used for electricity usage estimation (see section 3.1) while meshblock level information is used for switching estimation (see section 3.2).

\subsection{Weather}

Weather information is available from the National Institute of Water and Atmospheric Research (NIWA). NIWA has a range of weather stations scattered across the North Canterbury region (see figure 1). For each ICP, we take the weather reading from the closest weather station. We then generate an average across all ICPs associated with a particular GXP to generate GXP level weather parameters. This provides us with two data-sets. As with demographic data, GXP level data is used for electricity demand estimation, while meshblock level data is used for switching estimation.

\section{Results}

We first investigate the electricity offtakes in the MainPower/North Canterbury region. Then we turn our attention to the actual switching decisions of the ICPs.

\subsection{Electricity Demand}

We use our panel data on GXP offtakes and the demographic information to explore the sensitivity of electricity demand to household characteristics and weather.

In Table 1 we aggregate across GXPs. This allows us to explore the effect of demographic variables, which vary in the cross-section. We find that rain and soil moisture have a negative impact on electricity usage, while temperature and hours of sunlight have 


\begin{tabular}{lrrrr}
\hline Variable & Coeff. & T-stat & Coeff & T-stat \\
\hline Constant & 2977.1077 & 3.0188 & 2481.4082 & 2.6657 \\
Rain & -0.42172231 & -0.417 & 0.28806895 & 0.31715 \\
Sun & 0.65279703 & 0.37923 & 2.4509189 & 2.3701 \\
Soil Moisture & -22.523171 & -1.7264 & -33.299149 & -3.5615 \\
Temperature & 16.080464 & 1.1728 & 4.5756082 & 0.37651 \\
ICP Density & -7545.9209 & -7.7247 & -7572.5424 & -7.6161 \\
Proportion Four Bedroom House & -312.17372 & -7.9881 & -310.44548 & -7.7723 \\
Proportion Household & & & & \\
Income 100001+ & 578.78461 & 7.0055 & 575.96347 & 6.8205 \\
Proportion Age 65+ & 181.72713 & 2.9826 & 186.33366 & 2.9911 \\
Dummy Feb & -462.11331 & -2.3525 & & \\
Dummy Mar & -516.56403 & -2.6182 & & \\
Dummy Apr & -662.01083 & -2.9868 & & \\
Dummy May & -681.33873 & -2.8033 & & \\
Dummy Jun & -610.3638 & -2.0214 & & \\
Dummy Jul & -420.72073 & -1.4164 & & \\
Dummy Aug & -497.21565 & -1.6702 & & \\
Dummy Sep & -705.22995 & -2.5437 & & \\
Dummy Oct & -607.16922 & -2.4692 & & \\
Dummy Nov & -300.98275 & -1.5325 & & \\
Dummy Dec & -64.083451 & -0.35779 & & \\
Soil Moisture*ICP Density & 76.639945 & 4.044 & 80.697296 & 4.2628 \\
\hline$R^{2}$ & 0.441 & & 0.394 & \\
\hline
\end{tabular}

Table 1: Whole sample model for electricity usage. Dependent variable is GXP offtake in a given month. Two specifications are fit, one including dummy variables for months, and the other without. Variables described as Proportions refer to the proportion of census respondents in a meshblock who answered affirmatively; i.e. Proportion Four Bedroom House refers to the proportion of census respondents who live in a four bedroom house.

a positive impact. This supports the hypothesis that electricity usage in the region is significantly impacted by use of irrigation, predominately a dry weather activity. Seasonal dummy variables suggest that peak electricity usage is in December and January.

Demographically, we find that higher incomes and greater numbers of retirees increase electricity usage. Interestingly, the proportion of four bedroom place of dwelling in a meshblock (a proxy for the prevalence of larger houses, since most dwellings in the region are 1-4 bedrooms) has a negative impact on electricity usage.

Lastly, by interacting ICP density with soil moisture, we uncover a positive term, indicating that electricity usage is less sensitive to soil moisture in more urbanised GXPs.

We next break the sample into individual GXPs. Table 2 shows the results of this. 
Since we have disaggregated the cross-sectional element of the data, we can no longer estimate demographic effects. However, it is interesting to examine the effects of weather variables.

Figure 5 shows the results of trying to explain electricity usage with weather variables alone. For Culverden33, Waipara33 and Kaiapoi11, the regular seasonal patterns in the data are well explained by seasonal patterns in weather. However, for Culverden66/Kaikoura33, Waipara66 and Southbrook33, performance is considerably weaker. Figure 6 shows results once monthly seasonal dummies are incorporated. Culverden66/Kaikoura33, in particular shows a much improved estimation, suggesting that seasonal tourist visitors in December/January can explain much of the fluctuations in usage.

\subsection{Switching Behaviour}

We next turn our attention to customer switching behaviour. Given that our electricity demand results suggest that customers may have varying electricity usage based upon weather effects and demography, we include these explanatory variables as factors that may make a customer more or less likely to switch. Specifically, we interact these variables with relative pricing, so that customers who potentially have high power bills are more likely to switch retailers when prices are materially different.

Given Contact's preponderance in the region, we also include dummy variables for each of the retailers, effectively allowing customers to have a preference for a particular firm over others.

Table 3 contains our results. Our basic result is that customers have a very strong preference for remaining with their incumbent retailer. With a coefficient for incumbent retailer of 5.9828, we can infer that if all prices were identical, a customer has probability $e^{-5.9828}=0.0025$ of switching to a given competing retailer. Our index of -11.7842 on price says that if an incumbent faced a competitor who was $10 \%$ cheaper, a customer would have probability $e^{-5.9828+0.1 \times 11.7842}=0.0080$ of switching; price competition has significant impact on customer churn. 


\begin{tabular}{|c|c|c|c|c|c|c|c|c|c|c|c|c|}
\hline Variable & \multicolumn{6}{|c|}{$\begin{array}{c}\text { Culverden66/ } \\
\text { Kaikoura33 }\end{array}$} & \multicolumn{2}{|c|}{ Southbrook33 } & \multicolumn{2}{|c|}{ Waipara33 } & \multicolumn{2}{|c|}{ Waipara66 } \\
\hline Constant & 5134.145 & 4.339 & 1978.702 & 7.077 & 1799.153 & 5.695 & 2539.375 & 7.370 & 1869.021 & 6.354 & 2034.989 & 2.731 \\
\hline Sun & 9.537 & 3.286 & -3.171 & -4.316 & 2.536 & 3.280 & -0.056 & -0.062 & -0.121 & -0.171 & 1.965 & 1.018 \\
\hline Soil Moisture & -125.150 & -5.824 & 25.345 & 7.606 & 3.271 & 0.747 & -0.794 & -0.186 & -15.838 & -4.405 & 3.281 & 0.323 \\
\hline Temperature & -31.021 & -1.123 & 18.133 & 1.839 & 1.951 & 0.218 & -4.441 & -0.374 & -9.528 & -1.145 & -8.471 & -0.400 \\
\hline$R^{2}$ & & 0.723 & & 0.754 & & 0.211 & & 0.006 & & 0.458 & & 0.041 \\
\hline Sun & -1.442 & -0.317 & 0.676 & 1.245 & 1.585 & 1.534 & -0.281 & -0.266 & -0.038 & -0.036 & 2.334 & 0.881 \\
\hline Soil Moisture & -59.253 & -1.960 & 2.927 & 0.905 & -11.649 & -1.872 & -22.826 & -3.369 & -18.015 & -2.519 & -36.707 & -2.362 \\
\hline Temperature & 5.937 & 0.219 & 9.653 & 2.017 & 18.629 & 2.339 & 7.946 & 0.860 & -9.661 & -1.170 & 23.082 & 1.106 \\
\hline Dummy Feb & -860.962 & -1.907 & -126.858 & -1.850 & -530.442 & -5.183 & -450.526 & -3.408 & -153.088 & -1.413 & -505.097 & -1.796 \\
\hline Dummy Mar & -1105.406 & -2.402 & 86.355 & 1.232 & -438.265 & -4.368 & -354.775 & -2.629 & -233.546 & -2.135 & -507.881 & -1.832 \\
\hline Dummy Apr & -2109.565 & -3.991 & 208.835 & 2.751 & -356.744 & -2.995 & -405.320 & -2.762 & -318.788 & -2.590 & -548.930 & -1.732 \\
\hline Dummy Sep & -2013.115 & -3.324 & 411.357 & 3.841 & -31.611 & -0.226 & 198.564 & 0.949 & -209.356 & -1.109 & 613.759 & 1.475 \\
\hline Dummy Oct & -1600.611 & -2.806 & 258.330 & 2.847 & 55.397 & 0.432 & 153.993 & 0.871 & -212.194 & -1.344 & 379.928 & 1.013 \\
\hline Dummy Nov & -567.619 & -1.247 & 89.862 & 1.270 & -174.642 & -1.758 & 142.831 & 1.052 & -288.000 & -2.488 & 242.743 & 0.847 \\
\hline Dummy Dec & -177.651 & -0.435 & 60.269 & 0.952 & -44.016 & -0.473 & 84.762 & 0.698 & -95.549 & -0.975 & 265.321 & 1.052 \\
\hline$R^{2}$ & & 0.847 & & 0.963 & & 0.666 & & 0.618 & & 0.690 & & 0.518 \\
\hline
\end{tabular}

Table 2: Individual GXP demand regressions. Columns are GXPs under consideration. For each GXP, we consider two specifications: one including monthly dummy variables and the other excluding them. 

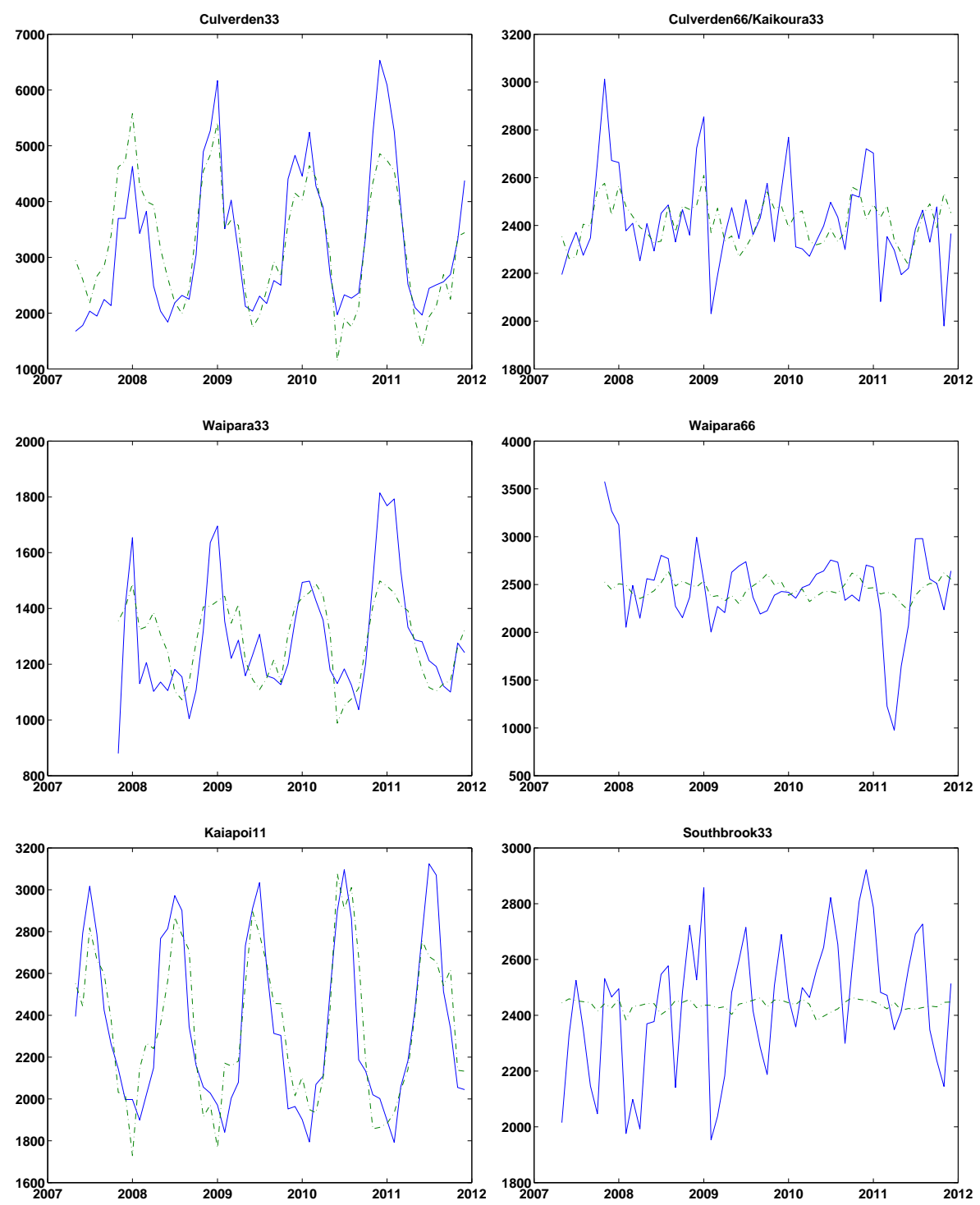

Figure 5: Electricity offtakes by Grid Exit Point. Solid line represents observed offtakes, dashed line represents fitted offtakes explained by weather variables. 

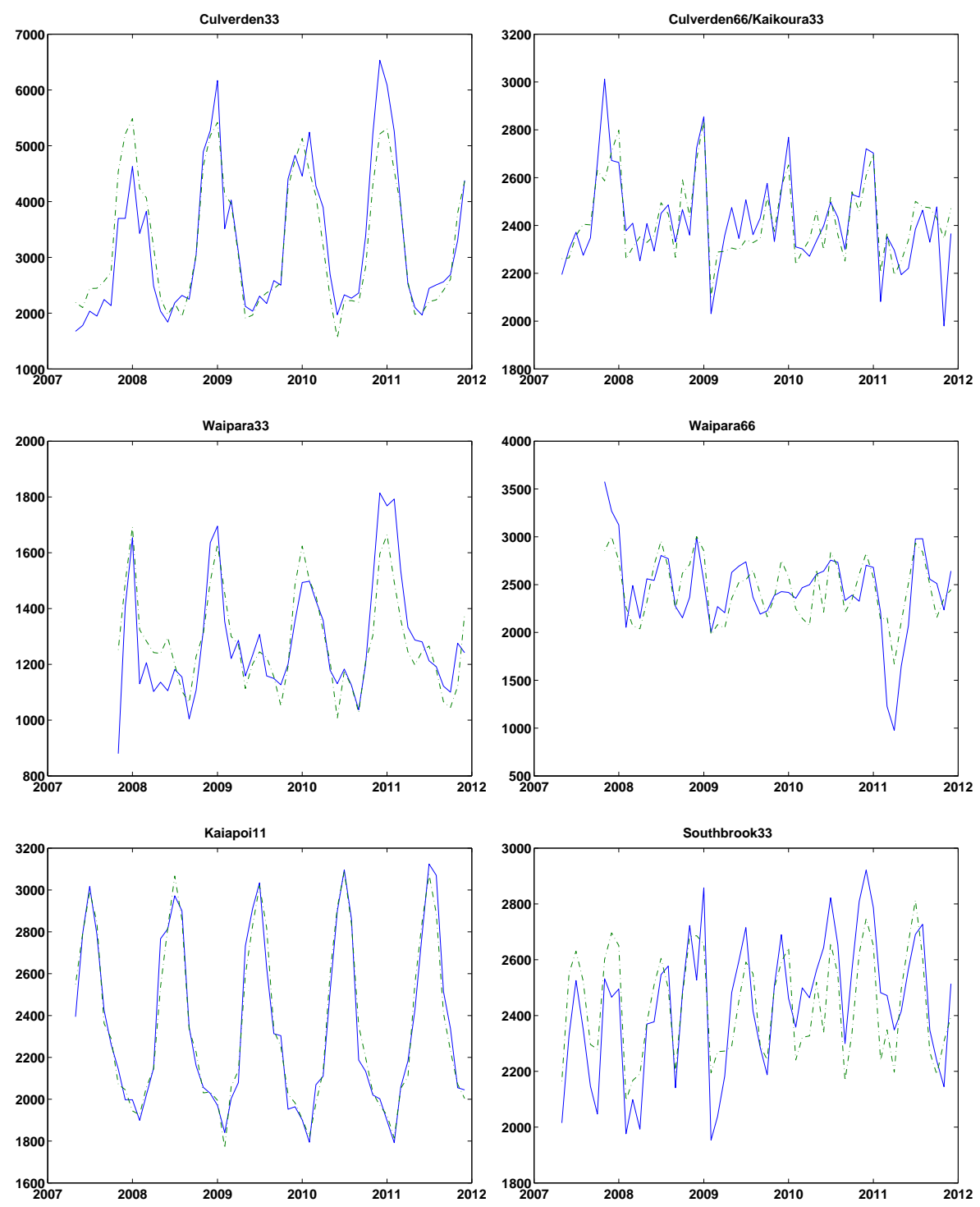

Figure 6: Electricity offtakes by Grid Exit Point. Solid line represents observed offtakes, dashed line represents fitted offtakes explained by weather variables, augmented by monthly dummies. 
Examining the Director Remuneration Incident, we find fairly weak effects in terms of customer movements. During the early months (September-November 2008) Contact in fact seemed to have better than usual retention of customers. However, December 2008 and January-March 2009 saw an outflow of customers. Indeed in January, with coefficient -0.8007, we would conclude that the director remuneration effect was the equivalent of a $6.8 \%$ price differential. Contact's approaching of former customers to "win them back" had the expected effect of increasing the likelihood of former Contact customers switching back to Contact except in month 6 (February 2009) when former Contact customers were less likely than usual to return to Contact. Given that this month follows the largest exodus month (January 2009) this may be seen to be the period in which the Director effect was strongest.

Next we turn our attention to the various marketing campaigns held in the region. The "What's my number?" campaign, unsurprisingly, decreased customer loyalty. Again, translating this to "discount equivalent" terms, this was equivalent in magnitude to a $4.97 \%$ price differential.

Interestingly, the largest effect is due to the Trustpower campaign, starting in February 2010, where Trustpower marketed itself as being New Zealand owned and being more desirable due to its trust governance structure. This campaign gave Trustpower the equivalent of a $15 \%$ price differential. Graphically, the effect of this campaign can be seen in Figure 3: from February 2010 onward, each winter, Trustpower market shares have risen, largely at the expense of Contact (as the incumbent) market shares.

The effect of Tiny Mighty Power's official "entry" into the market seems to have been largely negative. Examining Figure 3, Tiny Mighty Power had already gained a number of customers in the lead up to their official entry. It appears that their extra marketing around this time had little effect on customer switching.

The two earthquakes had opposite effects on ICP switches. Noting that considerable migration was caused by the two earthquakes, we might expect to see more switching, caused by customers moving into and out of the region. The first Canterbury Earthquake (September 2010) caused a significant increase in incumbent effects, while the second 
earthquake caused a decline in incumbent retention power.

Our company control variables are not surprising. Each of the non-Contact firms has a negative coefficient. Many customers have a strong preference for Contact. Interestingly, Trustpower's number is the most negative, reflecting its small market share prior to the marketing campaign. However, the effect of the campaign is to largely offset this, resulting in Trustpower being the second most popular retailer in the latter part of the sample.

Examining demographic effects, we find that large households and elderly households exhibit less sensitivity to prices, while high income households are more sensitive. These findings echo the survey evidence of (Giulietti et al. 2005). As might be suggested by Figure 3 most switching goes on in the winter, as exhibited by the higher sensitivity to prices during rainy months.

\subsubsection{Movers}

One concern with our work would be that many ICPs do not switch during the sample period. This could raise an identification issue, in that with little movement, it would be difficult to distinguish between preference for the retailer who happens to be an ICP's retailer at the start of the sample, and the incumbent ICP, since these would be one and the same for non-switching ICPs. To examine whether this affects the results, we next restrict our sample to ICPs who have switched at least once in the sample period, effectively excluding "non movers".

The results are reported in Table 4. Our basic finding regarding the strength of the incumbent effect is robust. Our coefficients for incumbent and relative price change from 5.9828 to 5.7557 and -11.7842 to -11.7114 . While the Incumbent coefficient difference is statistically significant, due to our large sample, the coefficient change is numerically similar. Repeating our calculation of the effect of a firm giving a $10 \%$ price cut, we find that the probability of attracting an ICP is $e^{-5.7557+0.1 \times 11.7114}=0.0102$. Not surprisingly, conditioning on ICPs that move, this sensitivity is slightly higher, but qualitatively similar.

Our examination of the Director Remuneration period also becomes slightly clearer 


\begin{tabular}{|c|c|c|c|c|c|}
\hline Variable & Coeff. & t-stat & Variable & Coeff. & t-stat \\
\hline Incumbent & 5.9828 & 341.2837 & & & \\
\hline Relative Price & -11.7842 & -44.3879 & & & \\
\hline \multicolumn{3}{|c|}{ Director Remuneration } & \multicolumn{3}{|l|}{ Events } \\
\hline Director 1 & 0.6285 & 4.3971 & What's my number? & -0.5855 & -17.0209 \\
\hline Director 2 & 0.7718 & 5.2021 & Trustpower campaign & 1.7676 & 30.8250 \\
\hline Director 3 & 0.7312 & 5.0216 & Contact TP campaign & 0.1271 & 3.5704 \\
\hline Director 4 & -0.4102 & -4.8307 & Tiny Mighty Power & -0.8422 & -2.9853 \\
\hline Director 5 & -0.8007 & -11.1519 & Sep. 2010 EQ & 0.5812 & 17.4911 \\
\hline Director 6 & -0.0573 & -0.5521 & Feb. 2011 EQ & -0.1623 & -3.7779 \\
\hline Director 7 & -0.3928 & -4.4210 & & & \\
\hline Director 8 & 0.4159 & 3.4267 & & & \\
\hline Director 9 & 0.2087 & 1.8955 & Price Interaction & & \\
\hline Director 10 & 0.2427 & 2.1750 & ICP Density & 0.0128 & 0.3774 \\
\hline Director 11 & 0.4693 & 3.7518 & Prop 4 bedrooms & 0.0013 & 2.1344 \\
\hline \multirow{2}{*}{ Director 12} & 0.0355 & 0.3461 & Prop 100K+ income & -0.0032 & -3.9218 \\
\hline & & & Prop Age 65+ & 0.0028 & 4.3241 \\
\hline Contact recovery & \multicolumn{2}{|c|}{ of lost customers } & Rain & -0.0011 & -8.0218 \\
\hline Old Cont. * Dir 1 & - & - & Sun & -0.0002 & -1.0231 \\
\hline Old Cont. * Dir 2 & 1.6459 & 1.6367 & Soil Moisture & 0.0000 & 0.0459 \\
\hline Old Cont. * Dir 3 & 0.8913 & 0.8884 & Temperature & -0.0022 & -1.1707 \\
\hline Old Cont. * Dir 4 & 1.5449 & 2.6601 & ICP Dens.*Soil M. & 0.0003 & 0.3200 \\
\hline Old Cont. * Dir 5 & 1.0319 & 2.0392 & & & \\
\hline Old Cont. * Dir 6 & -0.9823 & -0.9794 & Firm dummies & & \\
\hline Old Cont. * Dir 7 & -0.0216 & -0.0372 & Meridan Dummy & -0.6831 & -32.9643 \\
\hline Old Cont. * Dir 8 & 0.3622 & 0.9506 & TMP Dummy & -0.5399 & -6.5264 \\
\hline Old Cont. * Dir 9 & 0.9095 & 3.2360 & Genesis Dummy & -1.7927 & -43.7674 \\
\hline Old Cont. * Dir 10 & 0.3272 & 0.9139 & Trustpower Dummy & -1.9869 & -36.4567 \\
\hline Old Cont. * Dir 11 & 0.6601 & 2.2571 & Mercury Dummy & -0.9539 & -20.5503 \\
\hline Old Cont. * Dir 12 & 0.8324 & 3.1761 & Pulse Dummy & -1.3121 & -12.8146 \\
\hline
\end{tabular}

Table 3: Results for customer switching behaviour. Incumbent gives ICP utility from remaining with current retailer. Price multiplied by retailer's price relative to incumbent gives utility from choosing said retailer (incumbent's relative price is 1 ). Director 1 - Director 12 give utility from choosing Contact from start of Director compensation period to 12 months after. Next coefficients give utility from choosing contact for a customer who left during the Director compensation period (i.e. utility from returning to Contact). "What's my number" is a term that affects incumbent retailer during the campaign; a negative term reduces customer loyalty. The Trustpower marketing campaign is considered for effects on Trustpower utility and Contact utility. Demographics and weather characteristics are interacted with relative price; hence a positive number indicates that the characteristic makes a customer more price sensitive. Dummy variables for firms capture Contact's position as incumbent retailer; other firms are less popular, ceteris paribus. T-stats are constructed using standard errors that are robust to errors clustered by ICP. 
cut. The initial response to the director remuneration amongst movers is across the board lower (more negative, or, where positive, less positive), suggesting that more mobile customers were moving away from Contact. However, examining the recovery of lost customers, these still suggest a strong response to incentives to return to Contact after the event.

Not surprisingly, the "What's my number?" campaign had a stronger effect on this group than on the population as a whole, although Trustpower's marketing was not as significant. Tiny Mighty Power's entry remains insignificant, and the Earthquake has similar effects on this subgroup as to the population as a whole.

Interestingly, we see stronger demographic and environmental effects for this subsample. Urban (high ICP density areas) are more price sensitive, as are areas with larger houses. Higher incomes are less sensitive, as are older people. Rain (winter) remains a source of higher price sensitivity, but this is coupled with sun and temperature. Soil moisture is still insignificant as an explanatory variable, but increases considerably in magnitude, both as coefficient and t-statistic. It is interesting to note that house size, income, and ICP density coefficients changed sign between the full sample and the sample of movers. This sheds some light on the population of movers versus non-movers. Movers with low income, large houses, and who live in urban areas are found to be more price sensitive. In contrast, in the whole population, people with high income, small houses, and who live in rural areas are more price sensitive. This suggests that non-movers may often be people with low income, large houses and who live in urban areas. Regardless of the sample, older individuals are less price sensitive, suggesting that these contribute both to the non-mover population, and also are less price sensitive even when mobile.

Laslty, our firm dummies reiterate that Contact enjoys a privileged position in the Mainpower region, although this is more muted than with the full sample, with lower t-statistics, and significantly lower (in absolute value) coefficients. 


\begin{tabular}{|c|c|c|c|c|c|}
\hline Variable & Coeff. & t-stat & Variable & Coeff. & t-stat \\
\hline Incumbent & 5.7557 & 326.9383 & & & \\
\hline Relative Price & -11.7114 & -43.2652 & & & \\
\hline \multicolumn{3}{|c|}{ Director Remuneration } & \multicolumn{3}{|l|}{ Events } \\
\hline Director 1 & 0.3484 & 2.4317 & What's my number? & -1.0183 & -27.3002 \\
\hline Director 2 & 0.4855 & 3.2601 & Trustpower campaign & 1.6433 & 28.8382 \\
\hline Director 3 & 0.4406 & 3.0196 & Contact TP campaign & -0.6364 & -17.1335 \\
\hline Director 4 & -0.7185 & -8.4000 & Tiny Mighty Power & -0.3630 & -1.3109 \\
\hline Director 5 & -1.1146 & -15.3424 & Sep. 2010 EQ & 0.6121 & 18.1047 \\
\hline Director 6 & -0.3718 & -3.5592 & Feb. 2011 EQ & -0.2345 & -5.3185 \\
\hline Director 7 & -0.7148 & -7.9852 & & & \\
\hline Director 8 & 0.1048 & 0.8608 & & & \\
\hline Director 9 & -0.1098 & -0.9935 & Price Interaction & & \\
\hline Director 10 & -0.0807 & -0.7202 & ICP Density & -0.1093 & -3.0733 \\
\hline Director 11 & 0.1550 & 1.2353 & Prop 4 bedrooms & -0.0028 & -4.6328 \\
\hline \multirow[t]{2}{*}{ Director 12} & -0.2836 & -2.7521 & Prop 100K+ income & 0.0019 & 2.2570 \\
\hline & & & Prop Age 65+ & 0.0014 & 2.1542 \\
\hline Contact recovery & \multicolumn{2}{|c|}{ of lost customers } & Rain & -0.0005 & -3.2974 \\
\hline Old Cont. * Dir 1 & - & - & Sun & 0.0008 & 5.3075 \\
\hline Old Cont. * Dir 2 & 2.0250 & 2.0090 & Soil Moisture & 0.0014 & 1.2933 \\
\hline Old Cont. * Dir 3 & 1.2883 & 1.2837 & Temperature & 0.0067 & 3.3163 \\
\hline Old Cont. * Dir 4 & 1.9278 & 3.3237 & ICP Dens. ${ }^{*}$ Soil M. & 0.0013 & 1.1569 \\
\hline Old Cont. * Dir 5 & 1.4037 & 2.7724 & & & \\
\hline Old Cont. * Dir 6 & -0.6048 & -0.6034 & Firm dummies & & \\
\hline Old Cont. * Dir 7 & 0.3590 & 0.6183 & Meridan Dummy & -0.0420 & -2.0607 \\
\hline Old Cont. * Dir 8 & 0.7576 & 1.9903 & TMP Dummy & -0.1718 & -2.0439 \\
\hline Old Cont. * Dir 9 & 1.2988 & 4.6229 & Genesis Dummy & -1.2498 & -30.5762 \\
\hline Old Cont. * Dir 10 & 0.7142 & 1.9953 & Trustpower Dummy & -1.4203 & -26.6994 \\
\hline Old Cont. * Dir 11 & 1.0585 & 3.6217 & Mercury Dummy & -0.3977 & -8.0032 \\
\hline Old Cont. * Dir 12 & 1.2295 & 4.6891 & Pulse Dummy & -0.7278 & -6.4281 \\
\hline
\end{tabular}

Table 4: Results for customer switching behaviour, where sample is restricted to customers who switched at least once during the sample period. Variables are as discussed in Table 3. 


\section{Conclusion}

This paper examines the effect of consumer sensitivity to governance aspects of retailers/gentailers, over and above responsiveness to price differences. We find that there was a small response by Contact customers to news about Contact's Directors' compensation packages. However, more significant customer movements occurred in response to Trustpower's marketing of itself as having a more desirable governance structure to its competitors. Was this partly made more effective by being preceded by the remuneration incident? It is difficult to say.

Potential areas for future research would be to obtain more disaggregated data for electricity usage, allowing for better control for monthly bill size on switching behaviour. Examining effects in other regions could also be fruitful, since results for North Canterbury may be different due to Contact's dominant position in the retail market there.

\section{References}

Arnot, Chris, Peter C. Boxall, and Sean B. Cash (2006), Do Ethical Consumers Care About Price? A Revealed Preference Analysis of Fair Trade Coffee Purchases, Canadian Journal of Agricultural Economics 54, 555-565.

Bénabou, Roland and Jen Tirole (2006), Incentives and Prosocial Behavior, American Economic Review 96, 1652-1678.

Brennan, Timothy J. (2007), Consumer preference not to choose: Methodological and policy implications, Energy Policy 35, 1616-1627.

Bushnell, James B., Erin T. Mansur, and Celeste Saravia (2008), Vertical Arrangements, Market Structure, and Competition: An Analysis of Restructured US Electricity Markets, American Economic Review 91.

Cameron, A. Colin, Jonah B. Gelbach, and Douglas L. Miller (2011), Robust Inference With Multiway Clustering, Journal of Business and Economic Statistics 29, 238249. 
Defeuilley, Christophe (2009), Retail competition in electricity markets, Energy Policy 37.

Giulietti, M., C. Waddams, and M. Waterson (2005), Consumer Choice and Industrial Policy: a study of UK Energy Markets, The Economic Journal 115, 949-968.

Giulietti, Monica, Luigi Grossi, and Michael Waterson (2010a), Price transmission in the UK electricity market: Was NETA beneficial?, Energy Economics 32.

Giulietti, Monica, Jesus Otero, and Michael Waterson (2010b), Pricing behaviour under competition in the UK electricity supply industry, Oxford Economic Papers 62.

Giulietti, Monica, Michael Waterson, and Matthijs R. Wildenbeest (2010c), Estimation of Search Frictions in the British Electricity Market, warwick Economic Research Papers, No. 940.

Hortaçsu, A., S. A. Madanizadeh, and S. Puller (2014), Power to Choose: An Analysis of Consumer Behavior in the Texas Retail Electricity Market, Working Paper.

Kalayci, Kenan and Jan Potters (2010), Buyer confusion and market prices, International Journal of Industrial Organization 29, 14-22.

Littlechild, Stephen (2009), Retail competition and electricity markets - expectations, outcomes and economics, Energy Policy 37.

McFadden, D. (1973), Conditional Logit Analysis of Qualitative Choice Behavior, in P. Zarembka, ed., Frontiers in Econometrics (Academic Press, New York, USA).

Puller, Steven L. and Jeremy West (2013), Efficient Retail Pricing in Electricity and Natural Gas Markets, American Economic Review 103, 350-355.

Sen, Sankar, Zeynep G urhan-Canli, and Vicki Morwitz (2001), Withholding Consumption: A Social Dilemma Perspective on Consumer Boycotts, Journal of Consumer Research 28, 399-417. 
Su, Xuejuan (2014), Have customers benefited from electricity retail competition?, Journal of Regulatory Economics Forthcoming.

Waddams Price, Catherine and Minyan Zhu (2013), Pricing in the UK retail energy market, 2005-2013, CCP Working Paper 13-12.

Wilson, Chris M. and Catherine Waddams Price (2010), Do consumers switch to the best supplier?, Oxford Economic Papers 62, 647-668. 